NASA Technical Memorandum 88908

AIAA-87-1746

\title{
Supersonic Through-Flow Fan Design
}

James F. Schmidt, Royce D. Moore, Jerry R. Wood, and Ronald J. Steinke

Lewis Research Center

Cleveland, Ohio

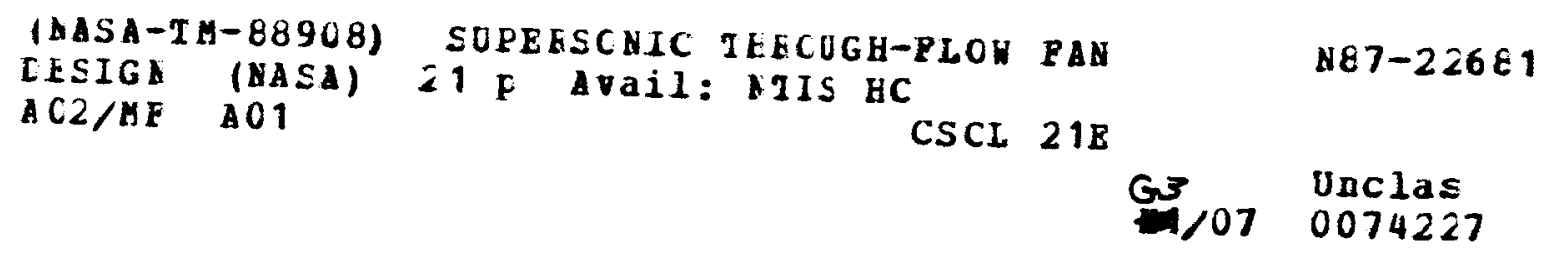

Prepared for the

23rd Joint Propulsion Conference

cosponsored by the AIAA, SAE, ASME, and ASEE

San Diego, California, June 29-July 2, 1987 


\section{SUPERSONIC THROUGH-FLOW FAN DESIGN}

James F. Schmidt, Royce D. Moore, Jerry R. Wood, and Ronald J. Steinke National Aeronautics and Space Administration

Lewis Research Center

Cleveland, Ohio 44135

\section{Abstract}

The NASA Lewis Research Center has embarked on a program to experimentally prove the concept of a supersonic through-flow fan which is to maintain supersonic velocities throughout the compression system with only weak shock-wave flow losses. This paper describes the detailed design of a supersonic through-flow fan and estimated off-design performance with the use of advanced computational codes. A multistage compressor facility is being modified for the newly designed supersonic through-flow fan and the major aspects of this modification are briefly described.

\section{Introduction}

The current desire to fly passengers across the Pacific Ocean at supersonic speeds of Mach 3 or greater 1 has created interest in developing better power plants to sustain efficient supersonic cruise. flight. At subsonic speeds, the turbof an engine has the thrust potential needed for take off and climb and is more efficient and quieter than the turbojet engine. 2 at supersonic cruise, the turbojet engine is generally more efficient than the turbofan engine. However, the turbofan engine equipped with a supersonic through-flow fan capable of accepting supersonic axial flow from the inlet has the potential of being very efficient at supersonic cruise conditions. In addition, the supersonic through-flow $f$ an has the potential of high pressure ratio as well as the advantage of accepting supersonic inlet Mach numbers without the 1 arge flow losses usually incurred by shocking down to subsonic flow in the inlet. The inherent shorter and lighter weight coupled with the advantage of potentially high pressure ratio with high efficiency for the supersonic compression system, makes this concept of prime interest for advanced high speed propulsion systems. Even with variable geometry for off-design operation, the resulting STF fan inlet is expected to be much shorter and lighter than a conventional supersonic inlet. The supersonic through-flow $f$ an is herein referred to as the STF fan.

Ferr $i^{3}$ was the first one to indicate the potential advantages of high fan pressure ratio (in single stage) and elimination of the subsonic portion of the supersonic inlet with the use of an STF fan. Franciscus ${ }^{4}$ showed that the STF fan equipped engine would significantly reduce specific fuel consumption compared with a conventional turbofan engine for a supersonic cruise mission. For a supersonic transport operating at a Mach number of 2.7, Tavares ${ }^{5}$ suggests that an STF fan efficiency of only 68 percent is necessary to have a performance advantage over a turbojet engine. These estimates of performance improvement from the cycle studies were based on assumed characteristics of the STF fan obtained from transonic fan data.

A11 of these cycle studies have an inherent uncertainty because of the lack of experimental data for the STF fan. A prototype STF fan rotor was designed, built, and tested by Breuge lmans. 6 However, before the design speed could be attained, a blade failure was encountered and the limited data obtained was insufficient to determine if supersonic through-flow was achieved.

Considering the 1 arge potential advantages of using a STF $f$ an in advanced propulsion systems, NASA Lewis has embarked on a program to experimentally prove the concept of an STF fan system. That is, can the supersonic through-flow velocities be maintained throughout the compression system and with only weak shock-flow losses? A multistage compressor facility is being modified to test a recently designed STF fan. The facility modifications essentially consist of adding a translating nozzle inlet and translating diffuser. This paper describes the detailed design of the STF $f$ an and estimated off-design performance with the use of advanced computational codes. In the absence of a STF fan experimental data base, these computational codes are essential tools for selecting potentially good blade shapes. With previous compressor-design experience and judicious aerodynamic design choices aided by the codes, blade shapes with poor performance can be avoided. The major aspects of the modified compressor facility are also discussed. The development, modification, and general applicability of these advanced computational codes used in the design and analysis of this STF fan system has been presented by Wood, et al.7

\section{Overall Fan Design Conditions}

Because of the absence of a fan data-base as well as the lack of previous analytical design and experimental experience for the STF fan, the following design criteria were selected early in the research program.

(1) Set the hub and tip radii constant throughout the fan stage to limit severe three-dimensional effects.

(2) Use a moderate overall pressure ratio of 2.45 and a rotor tip speed of $1500 \mathrm{ft} / \mathrm{sec}$ as representative of an STF $f$ an for a high speed power plant without being overly aggressive for this initial test experiment.

(3) Maintain supersonic through-flow velocities throughout compression system.

(4) Assure only weak shock-waves occur and the shock structure is captured within the bladed passages.

(5) Control suction and pressure surface gradients to minimize internal compression and expansion shock system strength.

In addition to the overall pressure ratio and rotor tip speed, Table 1 lists other fan design requirements such as hub-tip radius ratio $(0.7)$, design weight flow $(31.5 \mathrm{lb} / \mathrm{sec})$, tip diameter (10 in.), etc. 
Computational Codes

The fan design system consists of linking together the basic compressor design code (CDP) by Crouse and Gorre $11^{8}$ with an unpublished (in-house) blade element code (BEP) and a quasi-threedimensional viscous code (RVCO3) by Chima. ${ }^{9}$ These codes will now be discussed from the design standpoint of a code "user."

Compressor Design Code (CDP) and Blade Element Code (BEP)

The CDP code calculates the aerodynamic design of an axial-flow compressor and also the associated blading geometry that can be used as input for internal blade-to-blade flow analys is codes. This design code assumes steady inviscid axisymmetric flow and uses a streamline curvature method to determine the velocity diagrams at the blade edges along selected streamlines of revolution. A blade element is associated with each streamline of revolution. Each blade element has a centerline composed of two segments tangentially joined at a transition point. The local blade angle variation and blade element thickness distribution for each segment are specified with up to a fourth degree polynomial function of path distance. This definition of the blade element permits very general blade shapes and either circular or elliptical leading and trailing edges can be specified. For any inputed blade angle and blade thickness distribution an in-house blade element code (BEP) with a graphics package shows the blade shape and automatically gives the polynomial coefficients needed for the design code. After the blade element coordinates are defined, the blade elements are stacked along a prescribed line (usually radially) and the manufacturing blade section coordinates are defined from these stacked blade elements.

\section{Viscous Code (RVCO3)}

The RVCO3 code solves the unsteady Euler and thin-shear-layer Navier-Stokes equations for a quasi-three-dimensional flow. This viscous code accounts for the effects of rotation, radius change, stream surface thickness, and uses the BaldwinLomax eddy-viscosity model for turbulent flows. The RVCO3 code has a graphics package that displays line plots of blade st:pe, static pressure, Mach number, and total pressure as well as static pressure and Mach number contour plots of the complete flow field.

\section{Mechanical Design Codes}

The Nastran code was used to calculate the blade stress distribution for the rotor. Also, the rotor was analyzed for a potential flutter possibility with an in-house, unpublished flutter code.

\section{Fan Design Calculation Procedure}

The general design procedure for the rotor and stator is shown in Fig. 1 and starts with the CDP code. Overall fan specifications (see Table 1), initial incidence and deviation angles, initial blade shape geometry, and number of blades are needed for the first blade design calculation. The blade geometry depends upon several blade shape parameters described in the following section on the fan aerodynamic design. With the calculated blade geometry and flow conditions at the blade leading and trailing edges from the design code for several blade elements across span, the RVCO3 viscous code was used to determine if the following acceptable flow criteria were satisfied:

(1) Severe surface static pressure gradients do not exist on the blade elements that could produce strong shock-wave formation.

(2) The static pressure at the trailing edge of the suction and pressure surfaces are essentially the same such that the exiting flow from the blades will not have any strong shock waves.

(3) The leading edge shock wave must be weak and attached to the leading edge surface.

(4) From the Mach number contour plots, the unavoidable leading edge weak shock wave is contained by the expansion waves from the opposite surface and no strong shocks are generated in the flow passages or exiting flow.

(5) A recalculation of the deviation angle using the outlet flow angle from the viscous code is not significantly different from the design code value.

If these criteria were not satisfied, the blade shape geometry was revised in the blade element code (BEP) and the design procedure starting with the design code is repeated until a blade with the desired aerodynamic performance is obtained. After an acceptable design was achieved, a stress analysis was conducted on the blade to determine if mechanical integrity could be maintained. If the stress analysis indicated that the blade exceeded the acceptable stress limits, the blade was redesigned to satisfy both the aerodynamic flow and mechanical stress criterii. Before blade fabrication the final design was checked for flutter potential.

\section{Fan Aerodynamic Design}

Since an empirical data-base is not available for the supersonic through-flow (STF) fan, assumed incidence and deviation angles plus estimated total pressure losses across the rotor and stator were used in the design code. Suction surface incidence of zero degrees was used to minimize the leading edge shock wave and the deviation angle was obtained from the design procedure iteration. In addition to these assumptions, the effect of the blade geometry on the aerodynamic blade performance (that is strongly affected by the shock wave development) is relatively unknown in the compressor environment with supersonic axial inlet flow. However with systematic effort, the viscous analys is $\operatorname{code}^{9}$ can be used to deduce potentially good engineering approximations for incidence angle, deviation angle, and the effect of blade geometry on the aerodynamic blade performance. The blade geometry depend upon several blade parameters (Table 2) such as solidity, the maximum thickness to chord ratio, location of the maximum thickness to chord ratio, and the leading and trailing edge radi $i$ to chord ratios plus the blade angle and thickness distributions along the blade element. The following discussion will demonstrate how the blade geometry was selected for the STF fan that satisfies the essential overall criteria of maintaining supersonic through-flow velocites throughout the compression system. 
Before discussing the selection of the blade geometry, the first step is establishing the velocity (Mach number) diagrams (Fig. 2) which specify the mass flow and energy addition given the whee 1 speed and flow path geometry. The relative rotor Mach number varies from 2.36 at the hub to 2.70 at the tip with flow turning of $32^{\circ}$ at the hub to $22.6^{\circ}$ at the tip and the stator is designed to remove the rotor swirl.

\section{Rotor}

With the use of the fan design calculation procedure (Fig. 1) and the on-line graphics, changes in the blade geometry can quickly and easily be made to determine their effect on the blade aerodynamic performance.

\section{Effect of Solidity}

For supersonic flows one would expect that high solidity blades $(\sigma \gg 2.0)$ with longer chord should do a better job of handling the supersonic flow with a more controlled longer flow passage than conventional moderate solidity blades (21.0 to 2.0). Figure 3 shows the flow field for a low solidity $(21.0)$ rotor blade with an axial supersonic Mach number of 1.5. This initial blade shape with a typical transonic rotor tip solidity of 1.0 was used only during modification of the viscous code for supersonic through-flow. From the static pressure distribution in $\mathrm{Fig} .3$, a large mismatch of the surface static pressures occcurs at the trailing edge. This static pressure mismatch forces the flow to adjust by means of a strong shock wave formation at the trailing edge as indicated by the Mach number contour plot. Also, the velocity vector plot at the trailing edge (Fig. 3) indicates large boundary layer flow separation and abrupt change of flow direction which is a direct result of a very strong shock wave formation. Clearly, the STF fan blades should be designed with only weak shock waves contained within the covered blade passages.

In order to determine the value of solidity which might be appropriate for supersonic through flow, blades having three different solidities were analyzed. The viscous code calculations showing the effect of blade solidities from 2.5 to 3.75 on the static pressure distribution and Mach number contours are presented in Fig. 4. Increasing the solidity moved the point of minimum static pressure (maximum Mach number) on the suction surface toward the leading edge. At a solidity of 3.25 the point of minimum static pressure is located at about 50 percent chord and the trailing edge static pressures are about equal for the suction and pressure surfaces. It is very important that the static pressures at the trailing edge are essentially equal since then the flow can leave the blade almost tangent to the blade angle and no large adjustments (such as shock waves) to the flow are necessary at the trailing edge or downstream of the blade row. Also from Fig. 4, as the solidity is decreased the Mach number contour lines shows an increased concentration and then coalesce to form a shock wave at the lowest solidity (2.50). This shock wave would become stronger and move toward the trailing edge as the solidity is further decreased to one. The near hub section was used for this solidity study because the blade is thickest in the hub region with the largest leading edge wedge angle and thereby the strongest leading edge shock wave.
Results from this solidity study and further aerodynamic calculations for the mean and near tip sections of the blade incidate an essentially constant solidity of 3.25 from hub to tip would be desirable. However, the constant rotor blade solidity of 3.25 presents a serious mechanical design problem because now the tip chord must be significantly longer than the hub chord. This longer tip chord and hence greater mass of material in the tip region causes large mechanical stresses beyond the acceptable limit in the hub region. These large mechanical hub stresses can be reduced somewhat by decreasing the blade thickness in the tip region and/or increasing the blade thickness in the hub region. However, the blade thickness can be increased only so much before strong shock waves would result in poor aerodynamic performance. This occurs because the leading edge wedge angle increases with blade thickness.

After several iterations of the design procedure, the aerodynamic flow and mechanical stress criteria were satisfied with the following pre?iminary compromise design:

Rotor

$\begin{array}{lccc} & \begin{array}{c}\text { Blade } \\ \text { solidity }\end{array} & \begin{array}{c}\text { Max. thick } \\ \text { chord }\end{array} & \begin{array}{c}\text { Blade chord } \\ \text { in. }\end{array} \\ \text { Hub } & 3.56 & 0.07 & 3.56 \\ \text { Tip } & 3.11 & 0.04 & 4.45\end{array}$

The viscous flow calculations and the mechanical stress analysis strongly indicate that the blade solidity is the controlling design parameter for the supersonic through-flow fan.

\section{Effect of Blade Angle}

After determining the blade solidity which satisfied the desired aerodynamic flow and mechanical stress criteria, the blade angle distribution was varied to fine tune the flow distribution over the blade. A preliminary attempt for the blade angle distribution (Fig. 5) had a fairly sudden rise in blade angle near the leading edge which was used to decrease the leading edge wedge angle in order to reduce the strength of the leading edge shock wave. This rise was followed by a rapidly decreasing blade angle until mid-chord. The rear half of the blade had a linear blade angle distribution which produced a large static pressure gradient on the suction surface and practically no loading over the last 25 percent of the blade. The effect of the static pressure gradient on the suction surface is evident on the contour plot of Mach number by a significant increase in the viscous dominated region downstream of the location where a weak shock impacts the surface at about 50 percent of the chord. The final blade angle distribution shown in Fig. 5 yields much smoother static pressure distributions. The blade is loaded all the way to the trailing edge. Also, the static pressure on both the suction and pressure surfaces is equal at the trailing edge so that no strong adjustment of the flow downstream of the blade (like a shock wave) is required. From Fig. 6, the velocity vector plot at the trailing edge shows that the flow exits smoothly from the blade. The reduction in the static pressure gradients in the improved blade design (Fig. 5) results in Mach number contours which indicate a very thin viscous flow 
region. Also, the leading edge weak shock wave is completely contained in the covered flow passage and does not impact on the suction surface of the adjacent blade.

\section{Effect of Thickness Distribution}

Since the strength of the leading edge shock wave greatly increases with increasing leading edge radius, the radius was set at $0.005 \mathrm{in}$. (a radius which was considered the minimum machineable with reasonable accuracy).

With the use of the improved blade angle distribution, the effect of blade thickness distribution on the static pressure variation and Mach number contours is shown in Fig. 7 for the double circular arc (DCA) and improved polynomial curve fitted thickness distribution. The almost constant static pressure variation in the trailing edge region of the blade for the DCA thickness distribution produces essentially no loading over the last 20 percent of the blade. Also, the Mach number contour plot indicates a weak shock wave may be occurring at the trailing edge of the thicker DCA blade (Fig. 7). The static pressure distribution for the improved polynomial thickness distribution shows moderate blade loadings and a thinner more streamlined blade (especially evident over the rear portion of the blade) as seen by the Mach number contour plot.

\section{Final Blade Shapes}

Before presenting the final rotor blade design, it should be noted that it is almost impossible to determine all possible combination effects of design parameters. Often, multiple changes in design parameters produce unexpected results, especially in a new compressor flow regime. Probably only an advanced optimization analysis code would be able to select the best optimized design.

The final static pressure distributions and Mach number contour plots for the rotor blade sections near the hub, at the mean flow surface, and near the tip are shown in Fig. 8. Each blade section has similar static pressure distributions with little to no difference in static pressure between the suction and pressure surfaces at the trailing edge. The Mach number contour plots indicate that the leading edge shock wave is completely contained within the flow passage and does not impact on the adjacent blade surface. Wood ${ }^{7}$ applied a three-dimensional Euler code to the final rotor design and this resulted in very similar aerodynamic solutions as for the quasithree-dimensional code used in the design.

\section{Stator}

The same design philosophy used for the rotor was applied to the stator design. The entrance flow Mach to the stator is considerably higher than the relative rotor flow Mach number. Figure 9 shows the static pressure distributions and Mach number contour plots for the stator blade sections near the hub, mean, and near the tip. Each blade section has similar static pressure distributions with essentially equal static pressure for the suction and pressure surfaces at the trailing edge. The Mach number contour plots show the thicker viscous boundary layer region along the stator than for the rotor. This is indicative of the higher inlet Mach number for the stator but the leading edge weak shock wave is still contained within the flow passage and does not impact on the adjacent blade surface. The higher inlet Mach number for the stator (2.66 at the tip to 3.14 at the hub) necessitated slightly higher blade solidities (3.01 at the tip to 3.88 at the hub) than for the rotor in order to contain the shock wave within the covered flow passage. The optimum stator solidity would have been even higher but a flow calculation using an unpublished (quas i-threedimensional) off-design code suggested that the number of stator blades should be reduced to help alleviate a possible subsonic starting choke problem.

\section{Fan Mechanical Design}

The calculated blade stresses for the desired aerodynamic design of the STF rotor were too high. Thus a compromise was reached which reduced the relatively long tip chord that was causing excessive rotor hub stresses. Figure 10 shows the mechanical stress distribution for the rotor. The allowable rotor stress level for titanium is $100000 \mathrm{psi}$. The Campbell diagram for the rotor (Fig. 11) shows that the first mode bending frequency does not cross the frequency for the three and under excitations per revolution.

In addition, the effect of flutter on the rotor design was investigated with the use of a current in-house supersonic flutter code. This study resulted in a 30 percent increase in the rotor chord across the span in order to avoid a possible flutter problem.

\section{Off-Design Analysis}

\section{Incidence Angle}

At design supersonic speed, the viscous code was used to determine how the rotor sections might behave in an off-design mode. Figure 12 shows the effect of incidence $\left(-5^{\circ}\right.$ to $\left.+5^{\circ}\right)$ on the Mach number contours for the rotor at the near hub section. The most obvious result from Fig. 12 is that for this incidence range the flow remained orderly through the flow passages without any strong shock wave formation or large flow separation. The range of incidence for transonic compressors is about $6^{\circ}$.

\section{Fan Performance Map}

Off-design flow calculations were made for this STF fan with the use of an unpublished offdesign version of the axisymmetric design code. Figure 13 shows the predicted fan performance map with the fan pressure ratio plotted against weight flow for speed lines from 20 percent (low subsonic) to 100 percent of design speed (design supersonic flow). This fan performance map shows a wider operating range in the supersonic flow region than for the subsonic flow region. Looking at the transition region between subsonic and supersonic flow in Fig. 13, the off-design code predicts that the inlet axial flow will become supersonic between approximately 72 to 75 percent of design speed. Thereby, this off-design calculation predicts that with sufficient wheel speed and proper back pressure, the necessary weight 
flow will be obtained for starting the supersonic flow through the fan. During start up, it is highly desirable to have only a slightly supersonic normal shock wave move through the fan such that the smallest possible sudden pressure disturbance will be exerted on the blade rows.

\section{Facility Modifications}

The Lewis multistage compressor facility shown in Fig. 14 was chosen as the test facility because it has provisions for pressurized-dry inlet air, adequate power (15 $000 \mathrm{hp})$, and altitude exhaust system. The inlet plenum is connected to the Lewis central air supply system providing pressurized-dry inlet air up to 25 psia. The main modification to this facility will be to convert the inlet to essentially a supersonic wind tunnel. This will be accomplished by adding a translating nozzle inlet which can vary the $f$ an inlet Mach number between low subsonic and 2.1 . The entrance flow to the fan stage is controlled by this translating inlet, which is designed to produce a uniform parallel flow with a design axial Mach number of 2.0. A translating diffuser will be used as a throttle valve as well as the device to diffuse the flow to the altitude exhaust system. The STF fan test package as shown in Fig. 15 gives the physical description and location of the translating nozzle inlet, STF fan, and translating diffuser. In addition, bleed-flow capability to remove the boundary layer at the $f$ an and diffuser entrances will be designed into the STF $f$ an test package to help prevent end-wall boundary layer shock-wave interaction. A strong shock-wave in the diffuser section could produce a rapidly increasing tendency for an unstart flow condition.

\section{Concluding Remarks}

This paper has described the detailed design of a supersonic through-flow (STF) fan. The axisymmetric design code was used to design the $f$ an and the computational analys is codes have become essential tools for assessing the blade flow performance which results in selecting good final blade shapes. The iteration between the aerodynamic viscous flow and mechanical stress analysis codes strongly indicate that the blade solidity is the controlling design parameter for the STF fan. The rotor and stator for this STF fan are designed such that only weak controlled leading edge shock waves occur in the blade flow passages. These leading edge weak shock waves are contained within the covered flow passages without impacting on the adjacent blade surfaces and the flow leaves the blade trailing edge smoothly without any shock wave adjustments.

Also, the off-design flow calculations suggest that with sufficient wheel speed and proper back pressure, the necessary weight flow will be obtained for starting the supersonic flow through the fan in the planned test facility.

\section{References}

1. Driver, C., "How Different a Modern SST Would Be," Aerospace America, Vol. 24, No. 11, Nov. 1986, pp. 26-29.

2. McLean, F.E., "Supersonic Cruise Technology," NASA SP $-472,1985$.

3. Ferri, A., "Problems Related to Matching Turbojet Engine Requirements to Inlet Performance as a Function of Flight Mach Number and Angle of Attack," Air Intake Problems in Supersonic Propulsion, J. Fabri, Ed., Agardograph No. 27, AGARD, France, 1956, pp. 48-62.

4. Franciscus, L.C., "Supersonic Through-Flow Fan Engines for Supersonic Cruise Aircraft, " NASA TM-78889, 1978.

5. Tavares, T.S., "A Supersonic Fan Equipped Variable Cycle Engine for a Mach 2.7 Supersonic Transport," NASA CR-177141, 1985.

6. Breugelmans, F.A.E., "The Supersonic Axial Inlet Component in a Compressor," ASME Paper 75-GT-26, Mar. 1975.

7. Wood, J.R., Schmidt, J.F., Steinke, R.J., Chima, R.V., and Kunik, W.G., "Application of Advanced Computational Codes in the Design of an Experiment for a Supersonic Throughflow Fan Rotor," NASA TM-88915, 1987.

8. Crouse, J.E. and Gorrell, W.T., "Computer Program for Aerodynamic and Blading Design of Multistage Axial-Flow Compressors," NASA TP-1946, 1981.

9. Chima, R.V., "Development of an Explicit Multigrid Algorithm for Quasi-Three-Dimensional Viscous Flows in Turbomachinery," AIAA Paper 86-0032, Jan. 1986. 
TABLE I. - OVERALL STF FAN

DESIGN CONDITIONS

\begin{tabular}{|l|r|}
\hline Pressure ratio & 2.45 \\
Weight flow, ib/sec & 31.5 \\
Inlet axial Mach number & 2.0 \\
Tip speed, ft/sec & 1500 \\
Rotative speed, rpm & 17189 \\
Diameter, in. & 20 \\
Hub-tip ratio & 0.7 \\
\hline
\end{tabular}

TABLE II. - ROTOR AND STATOR DESIGN PARAMETERS

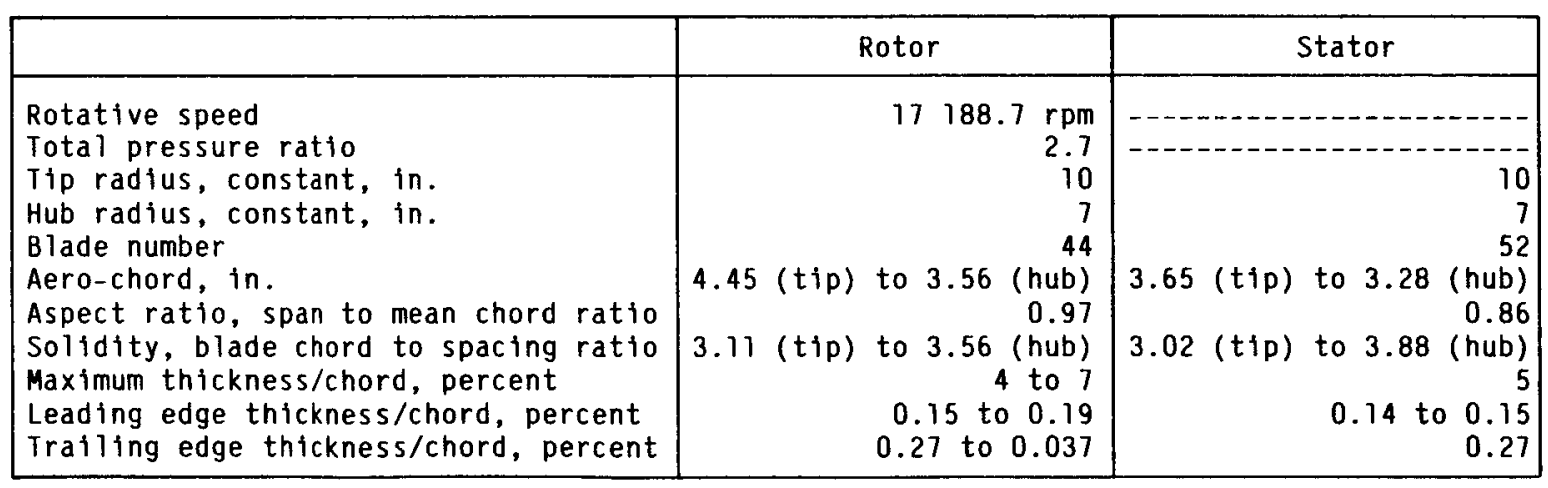


DESIGN POINT REQUIREMENTS

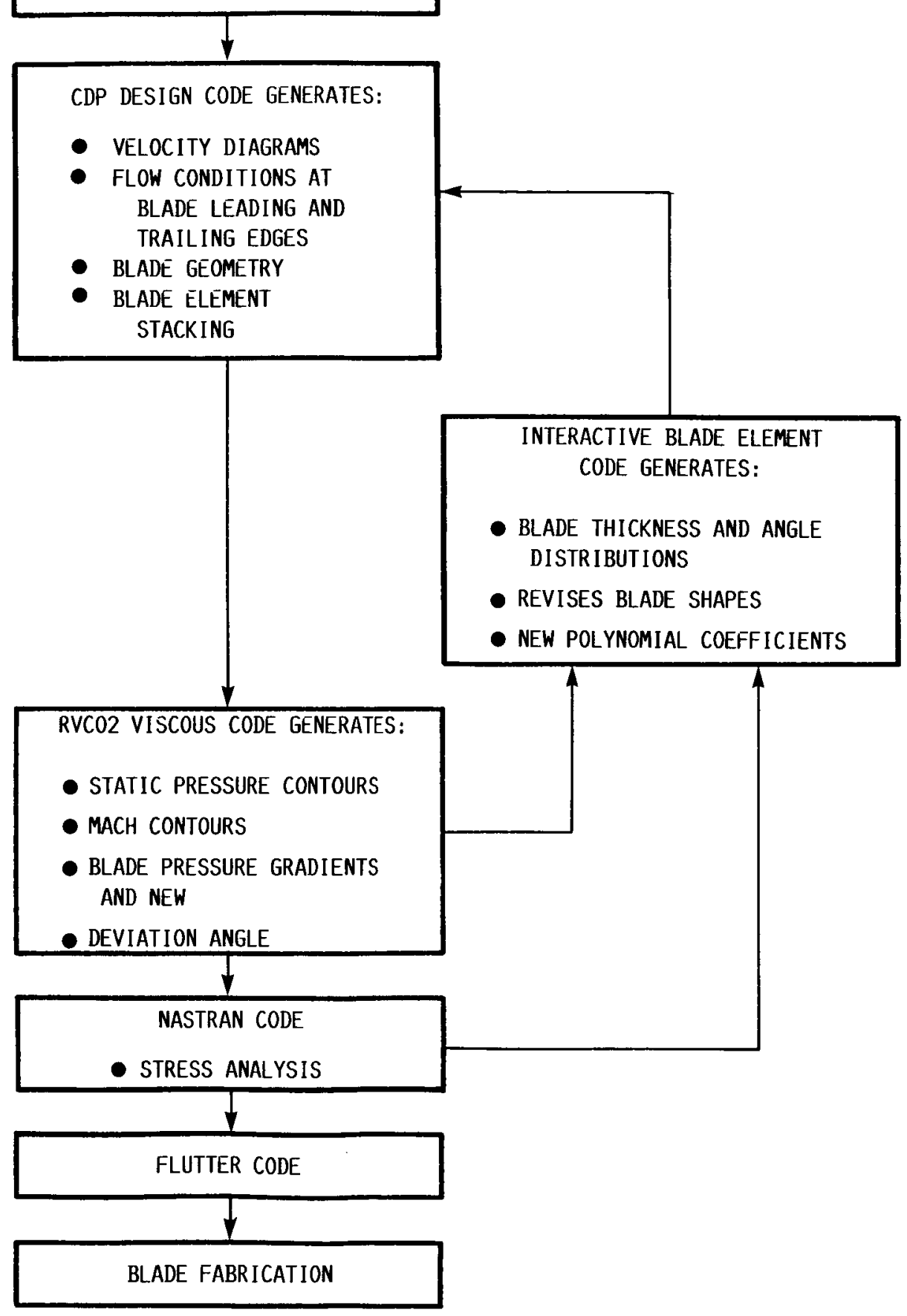

FiguRE 1. - FAN DESIGN CALCULATION PROCEDURE. 
MACH NUMBER

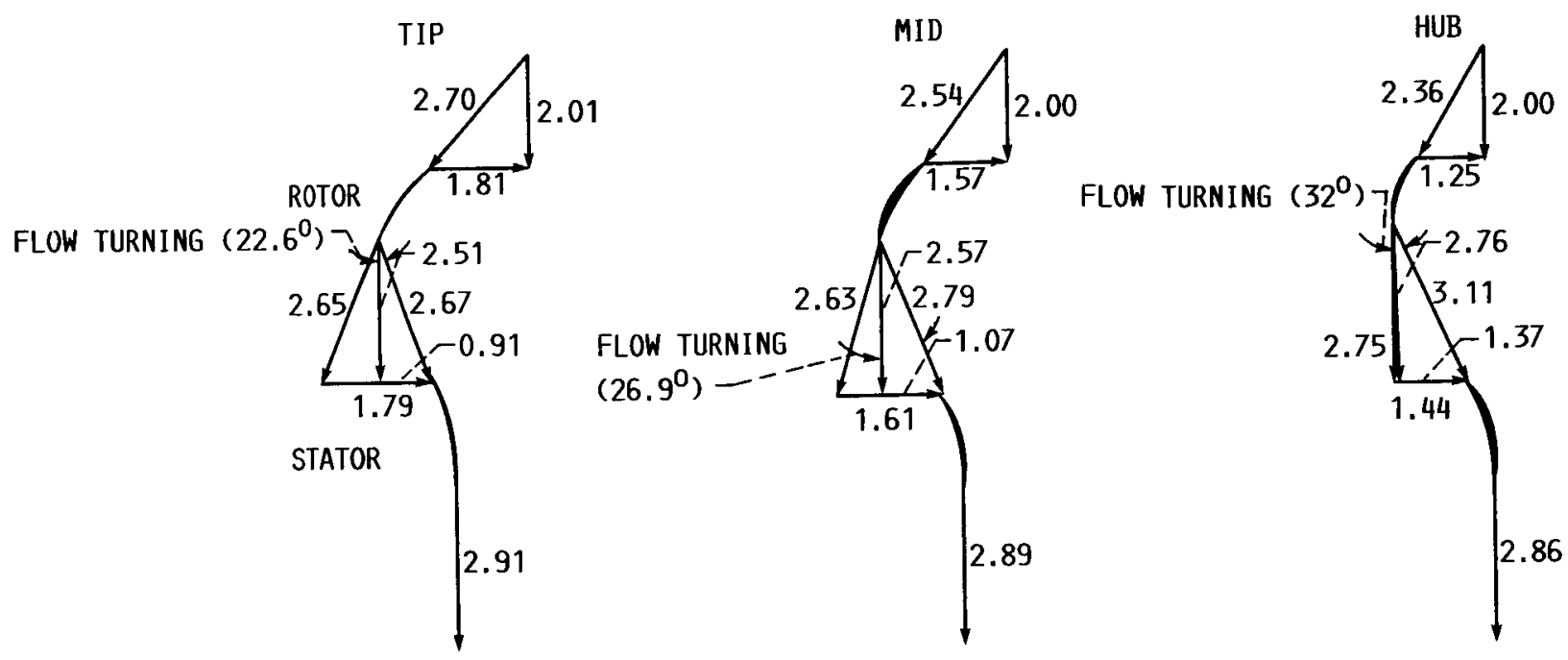

FIGURE 2. - STF FAN VECTOR DIAGRAMS.

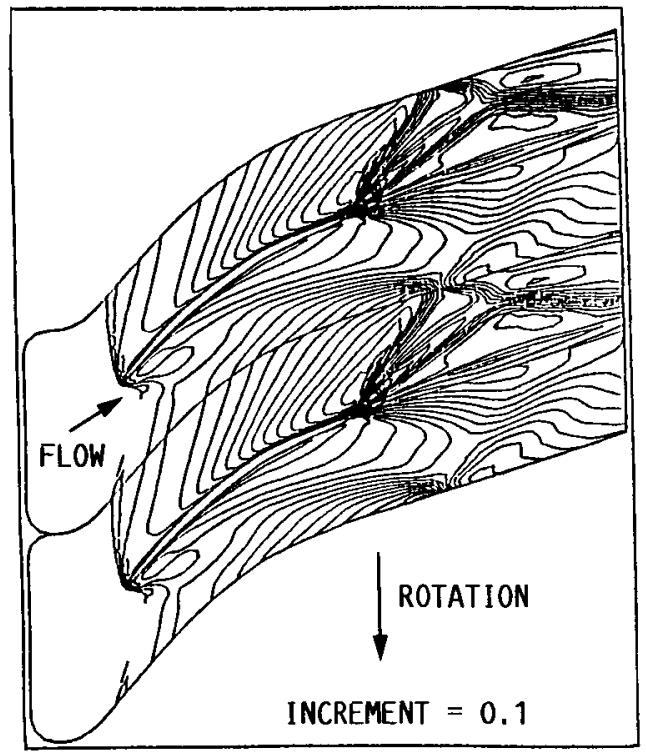

MACH NUMBER CONTOURS
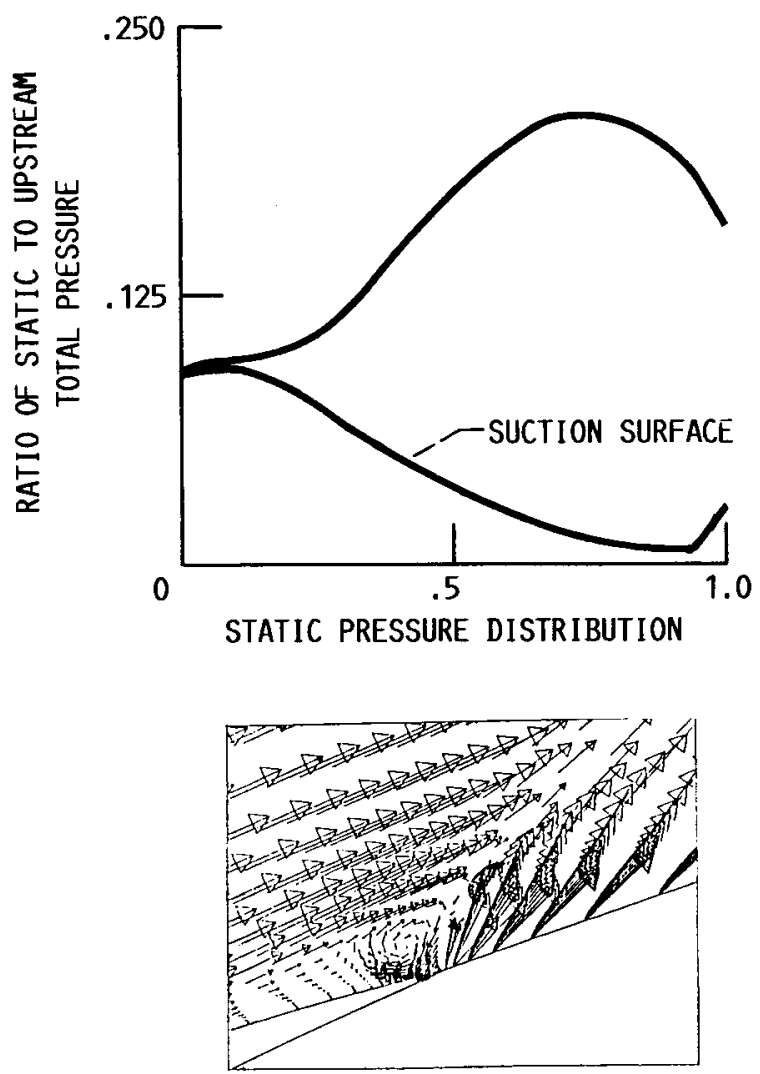

VELOCITY VECTORS AT TRAILING EDGE

FIGURE 3. - RESULTS OBTAINED WI TH THE VISCOUS CODE FOR THE EXAMPLE BLADE SHAPE (SOLIDITY, 1.0. AND INLET MACH NUMBER OF 1.5). 

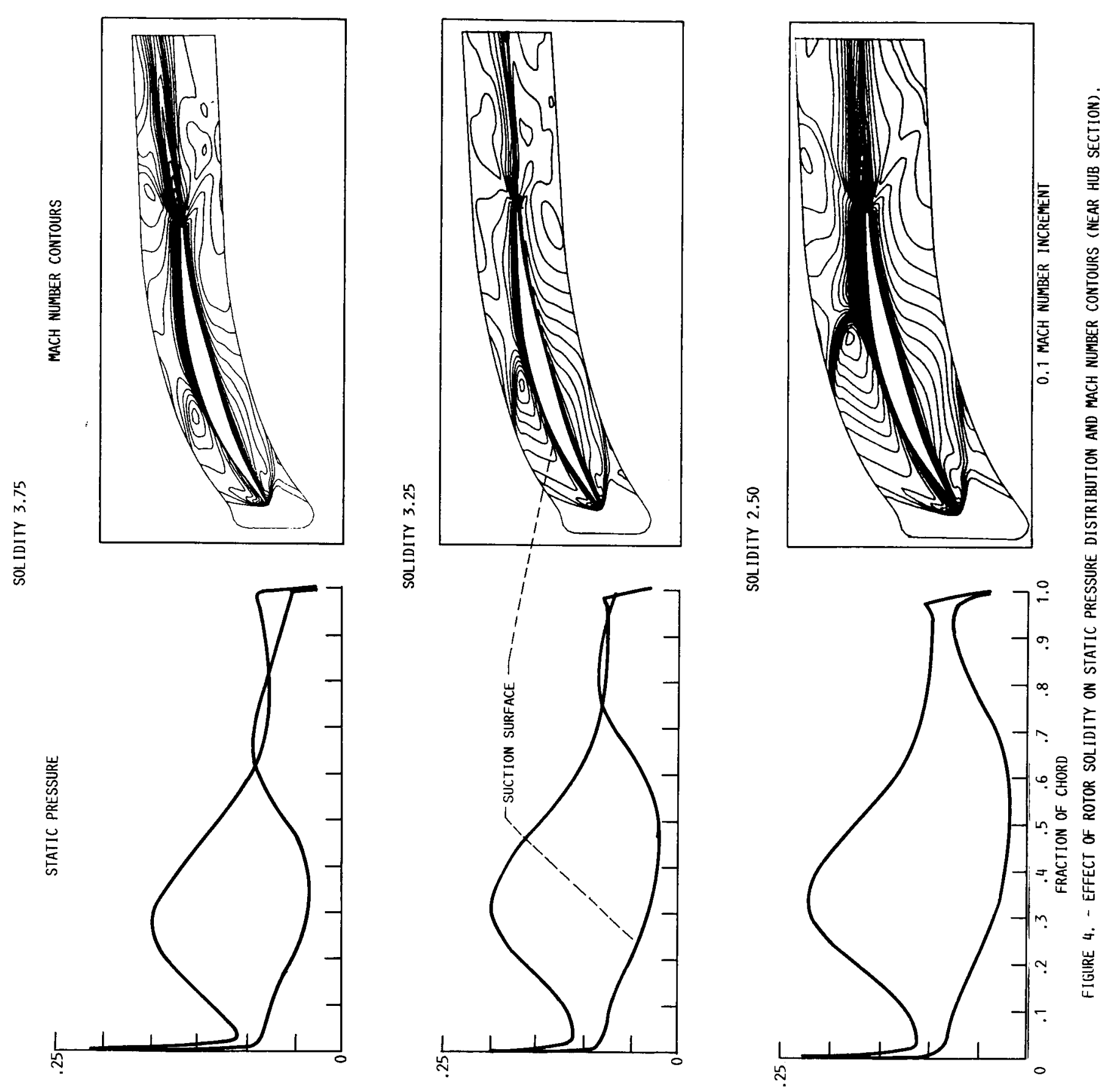

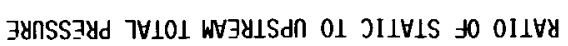


BLADE ANGLE

PREL IMINARY

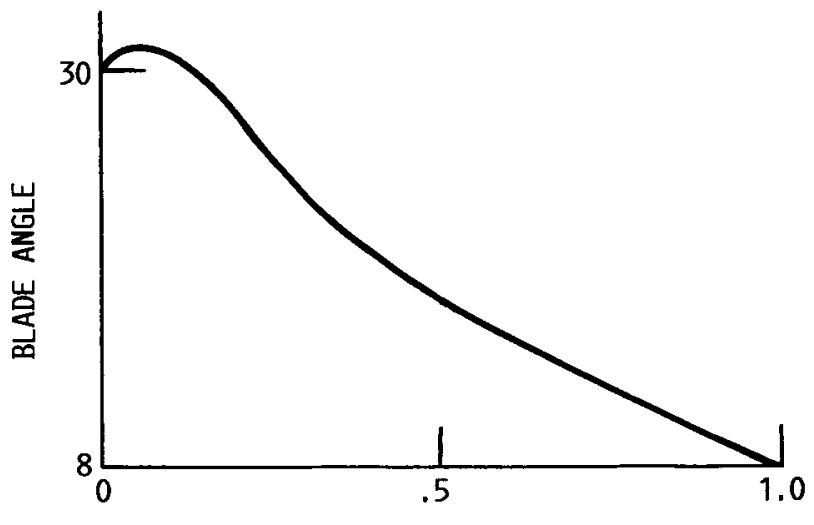

FINAL

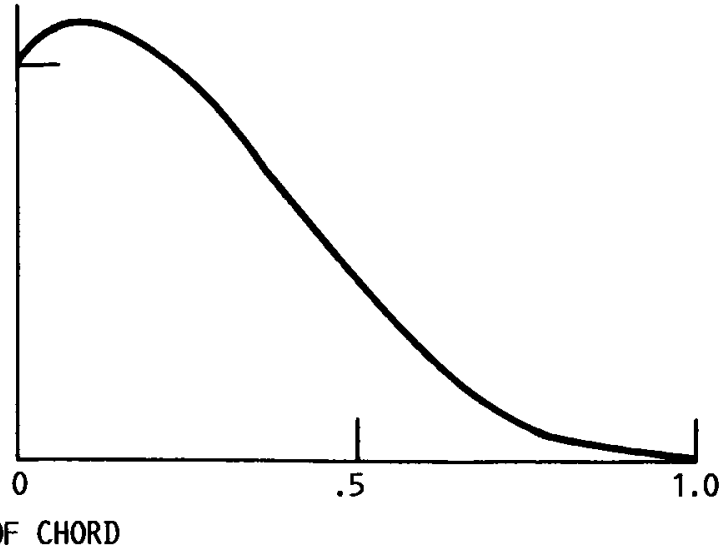

STATIC PRESSURE

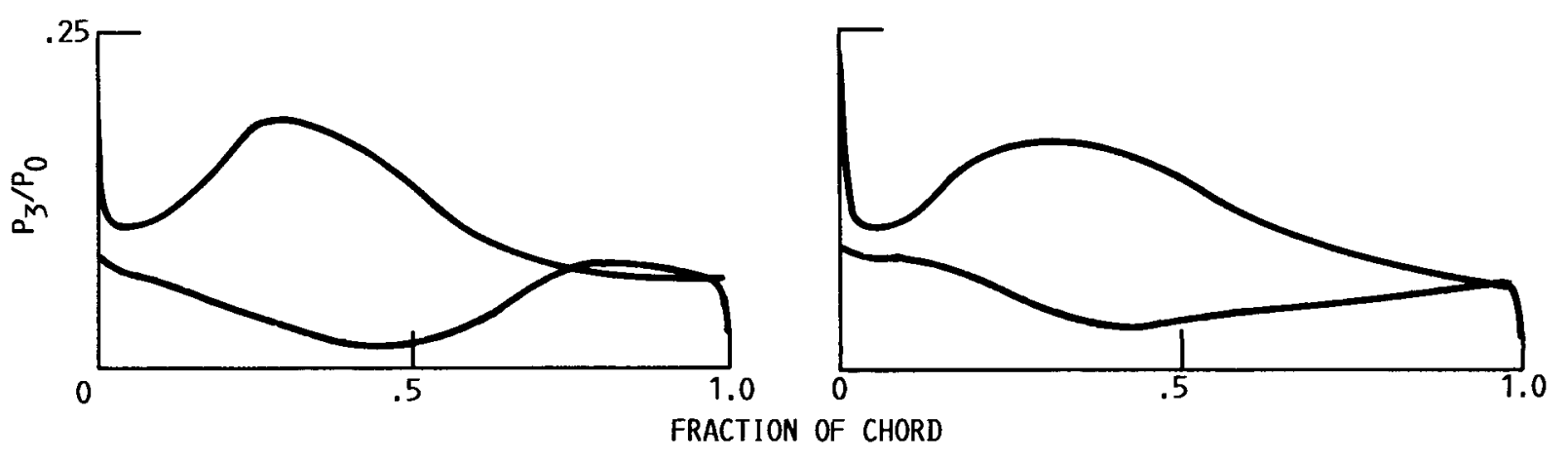

MACH NUMBER CONTOURS
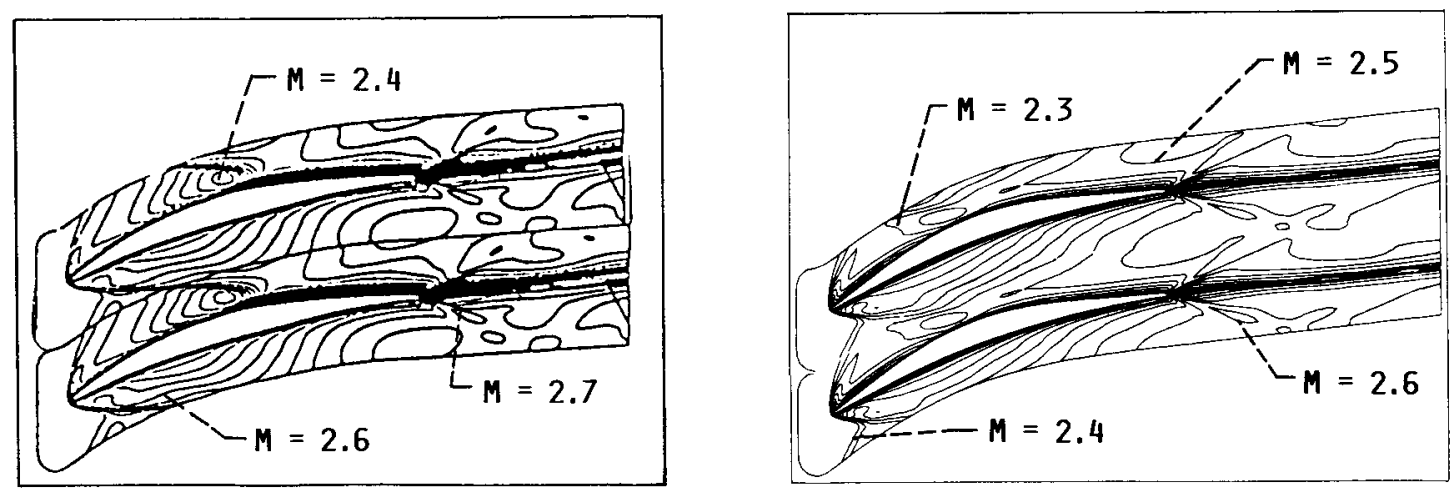

0.1 MACH NUMBER (M) INCREMENT

FIGURE 5. - EFFECT OF ROTOR BLADE ANGLE DISTRIBUTION ON THE STATIC PRESSURE DISTRIBUTION AND MACH NUMBER CONTOURS FOR THE NEAR HUB SECTION (SOLIDITY, 3.42). 


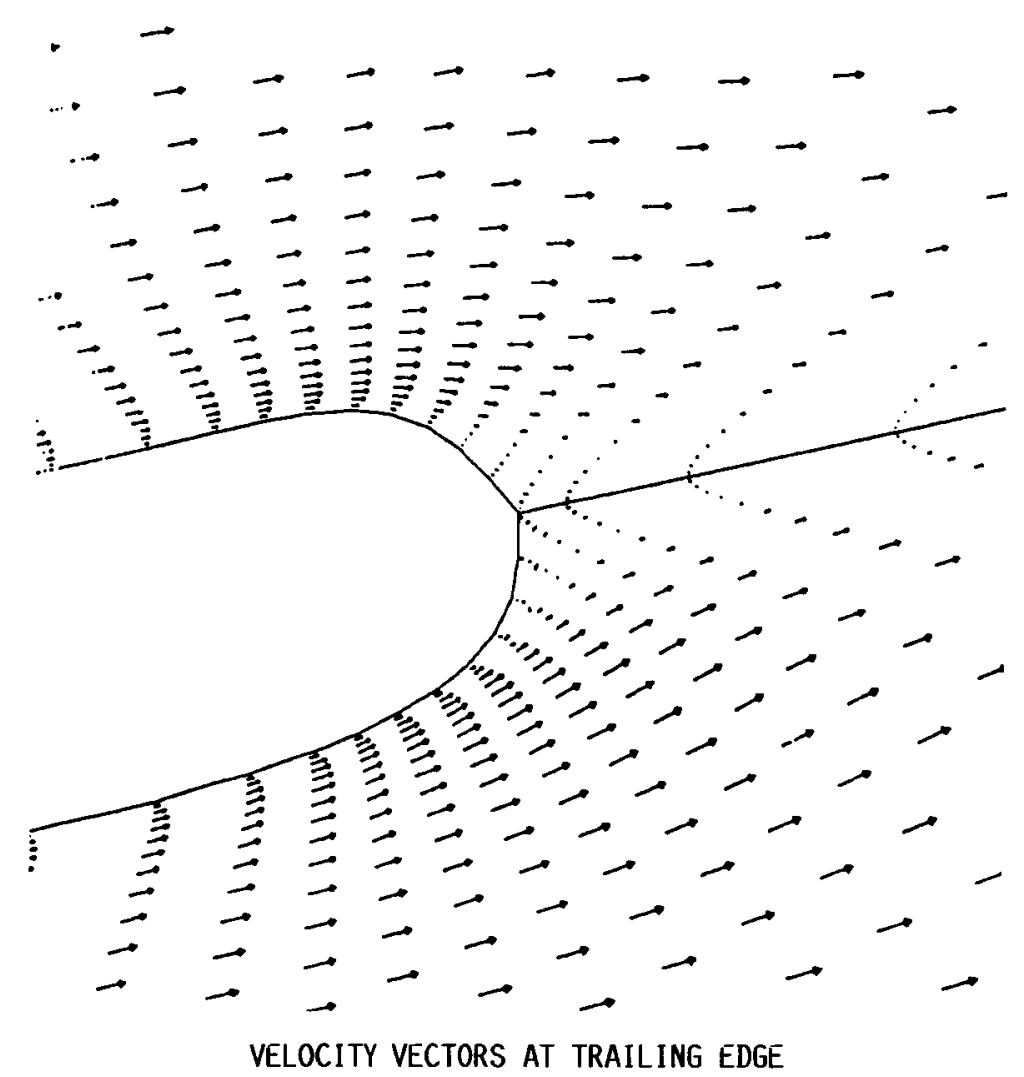

FIGURE 6. - DETAILED FLOW ANALYSIS FROM THE VISCOUS CODE FOR THE ROTOR TRAILING EDGE REGION FOR THE NEAR HUB SECTION (SOLIDITY, 3.42). 

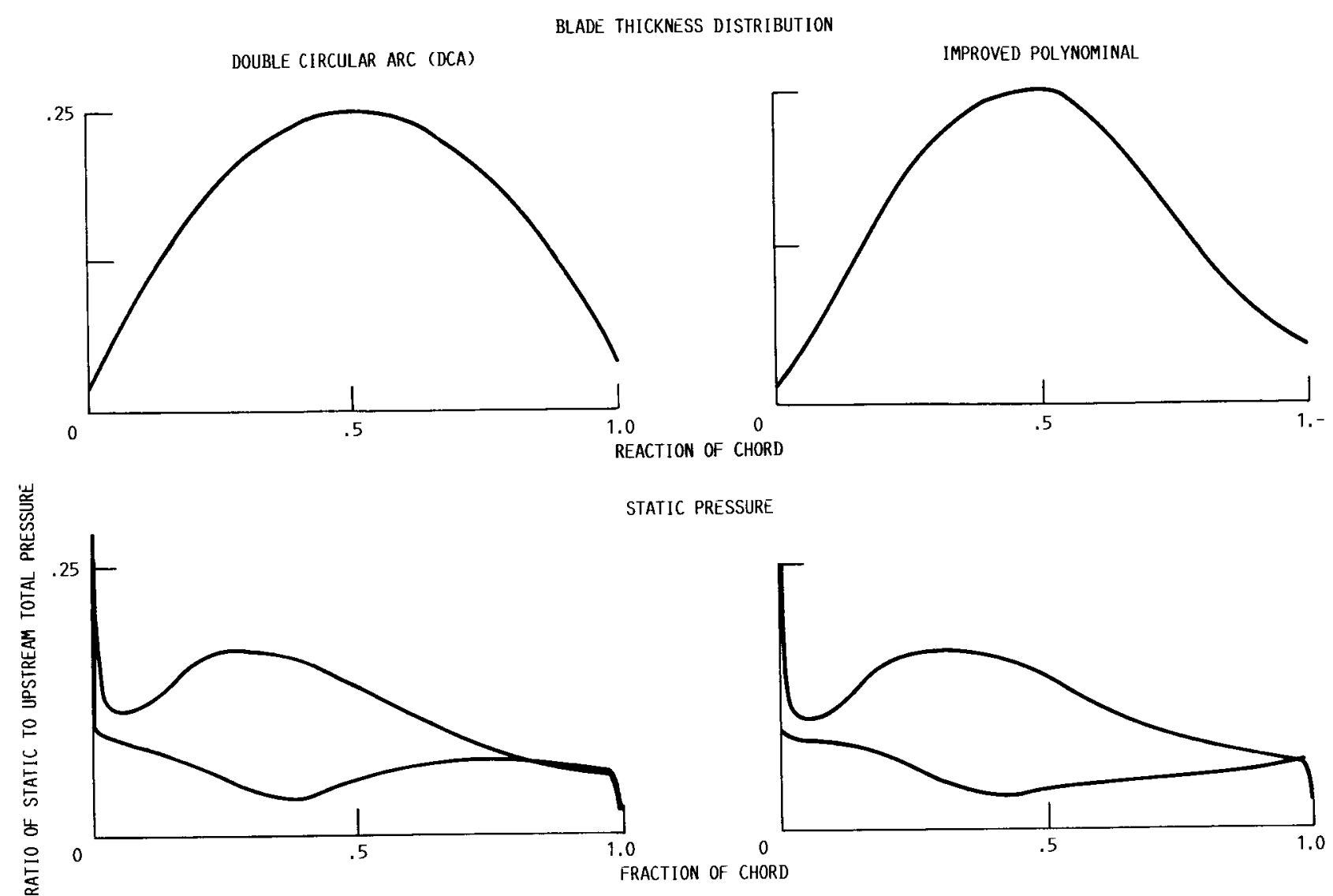

STATIC PRESSURE

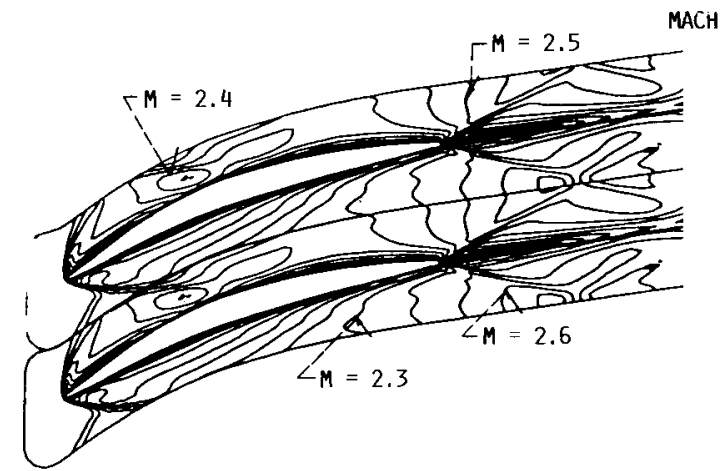

0.1 MACH NUMBER (M) INCREMENT

FIGURE 7. - EFFECT OF ROTOR BLADE THICKENSS DISTRIBUTION ON THE STATIC PRESSURE DISTRIBUtion AND MACH NUMBER CONTOURS FOR thE NEAR HUB SECTION (SOLIDITY, 3.42). 


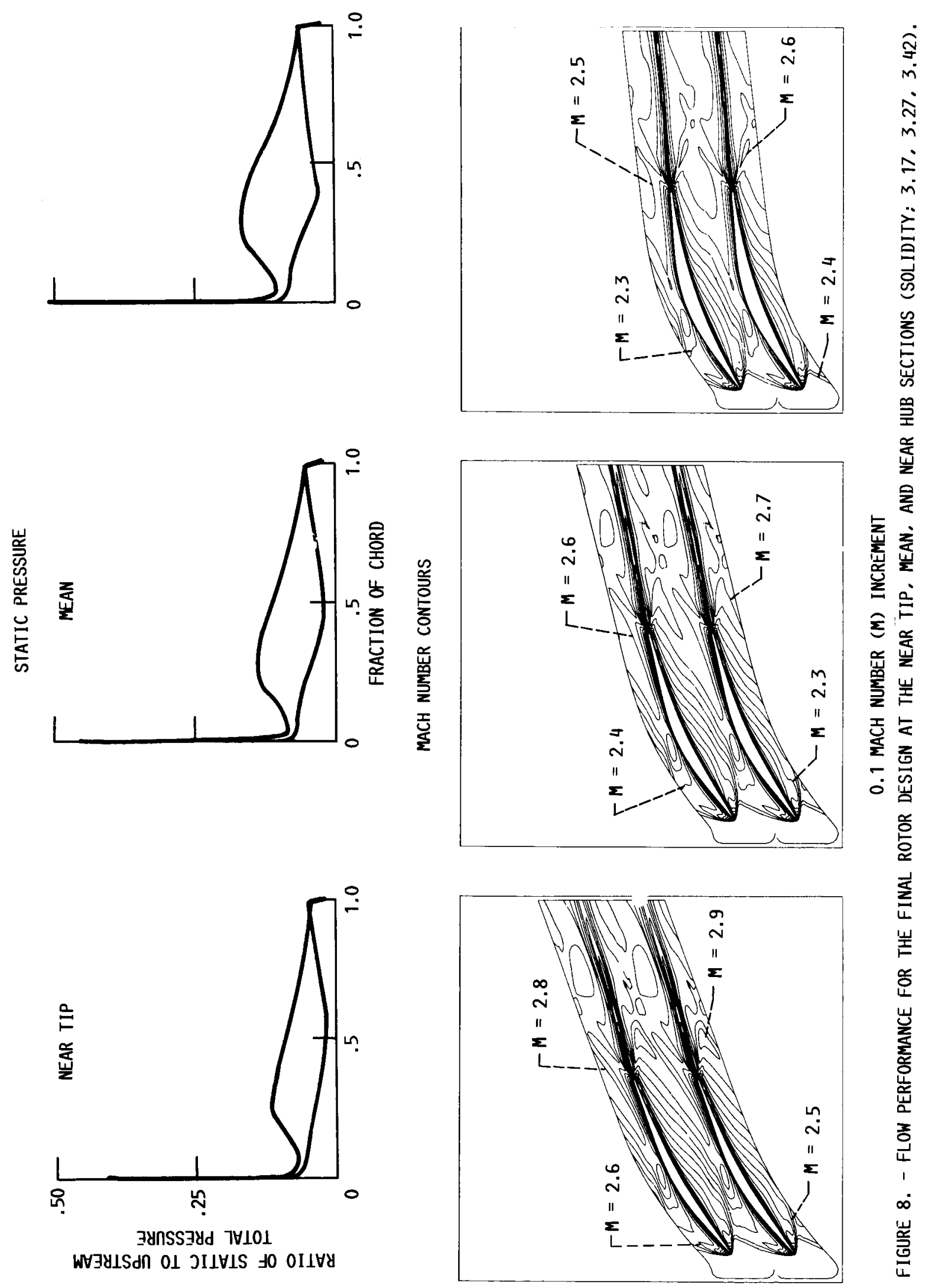




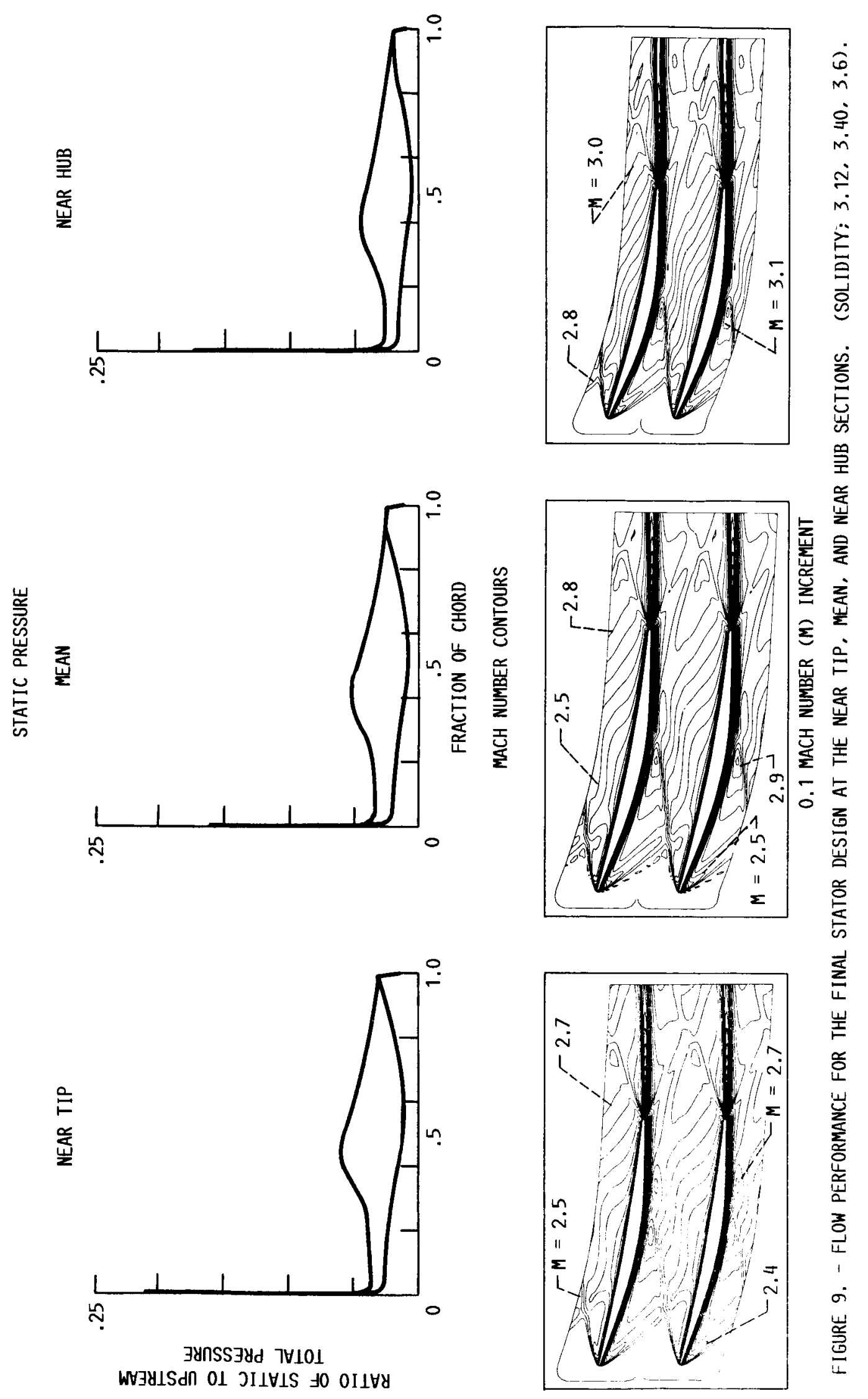




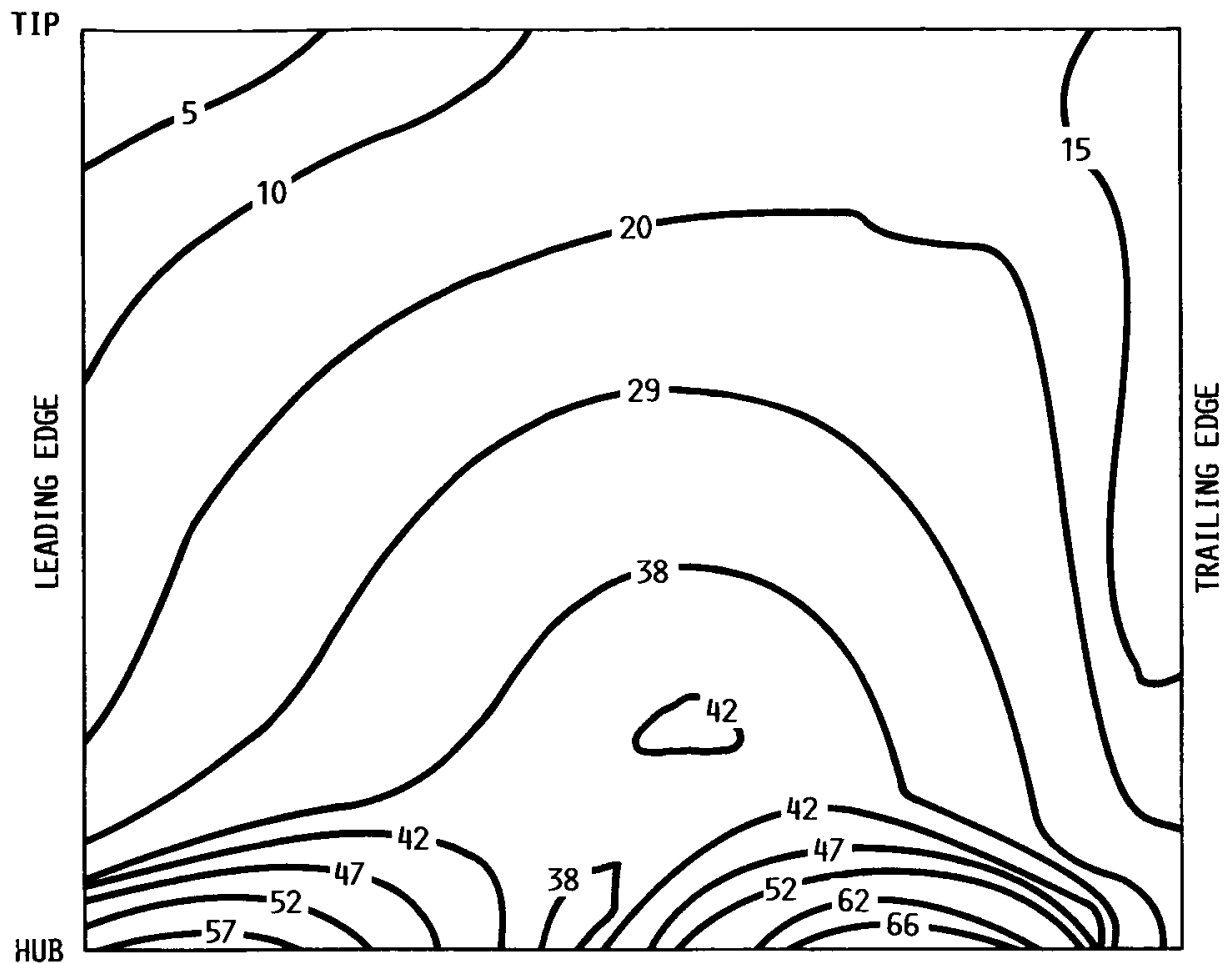

FIGURE 10. - CALCULATED STRESS DISTRIBUTION FOR THE ROTOR (STRESS IN KPSI).

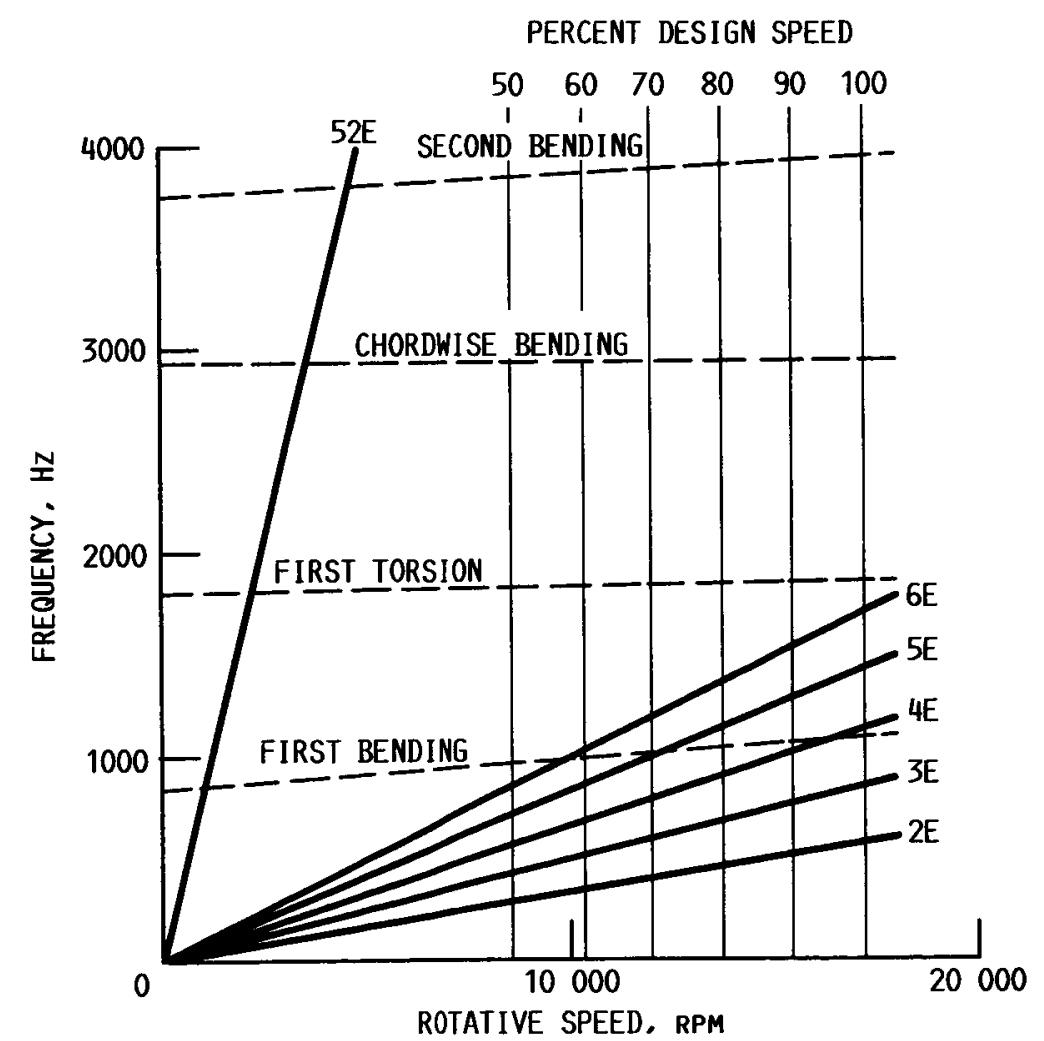

FIGURE 11. - CAMPBELL DIAGRAM FOR ROTOR. 


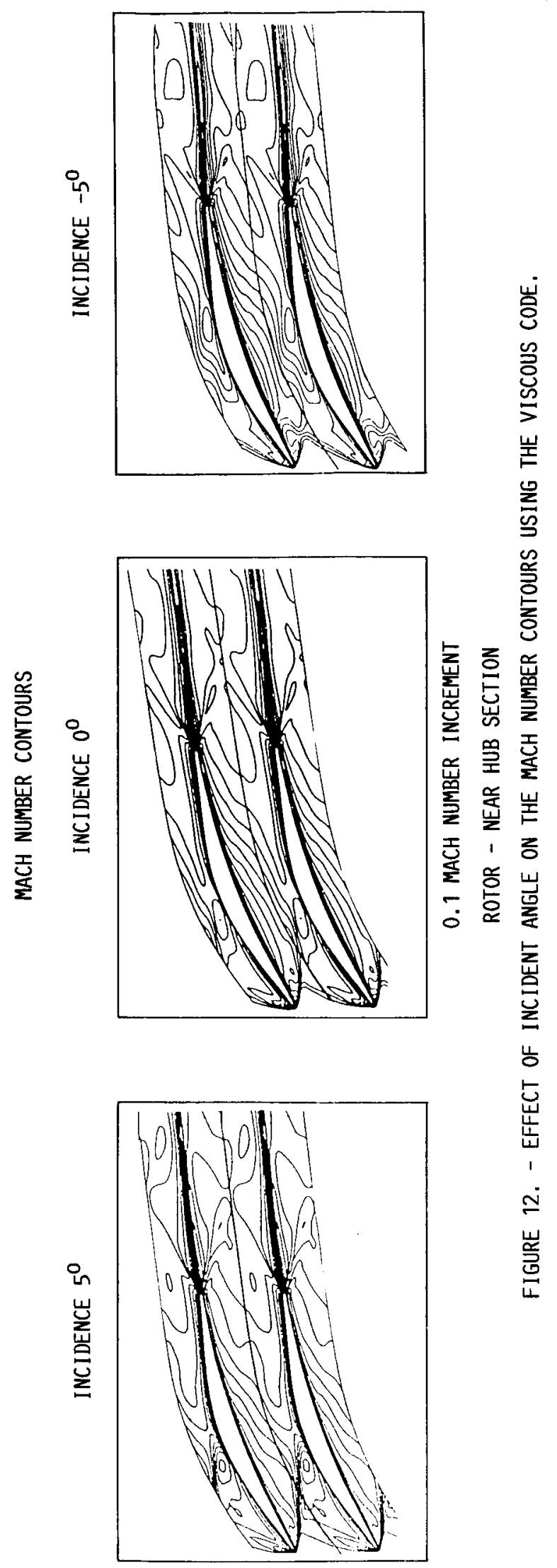




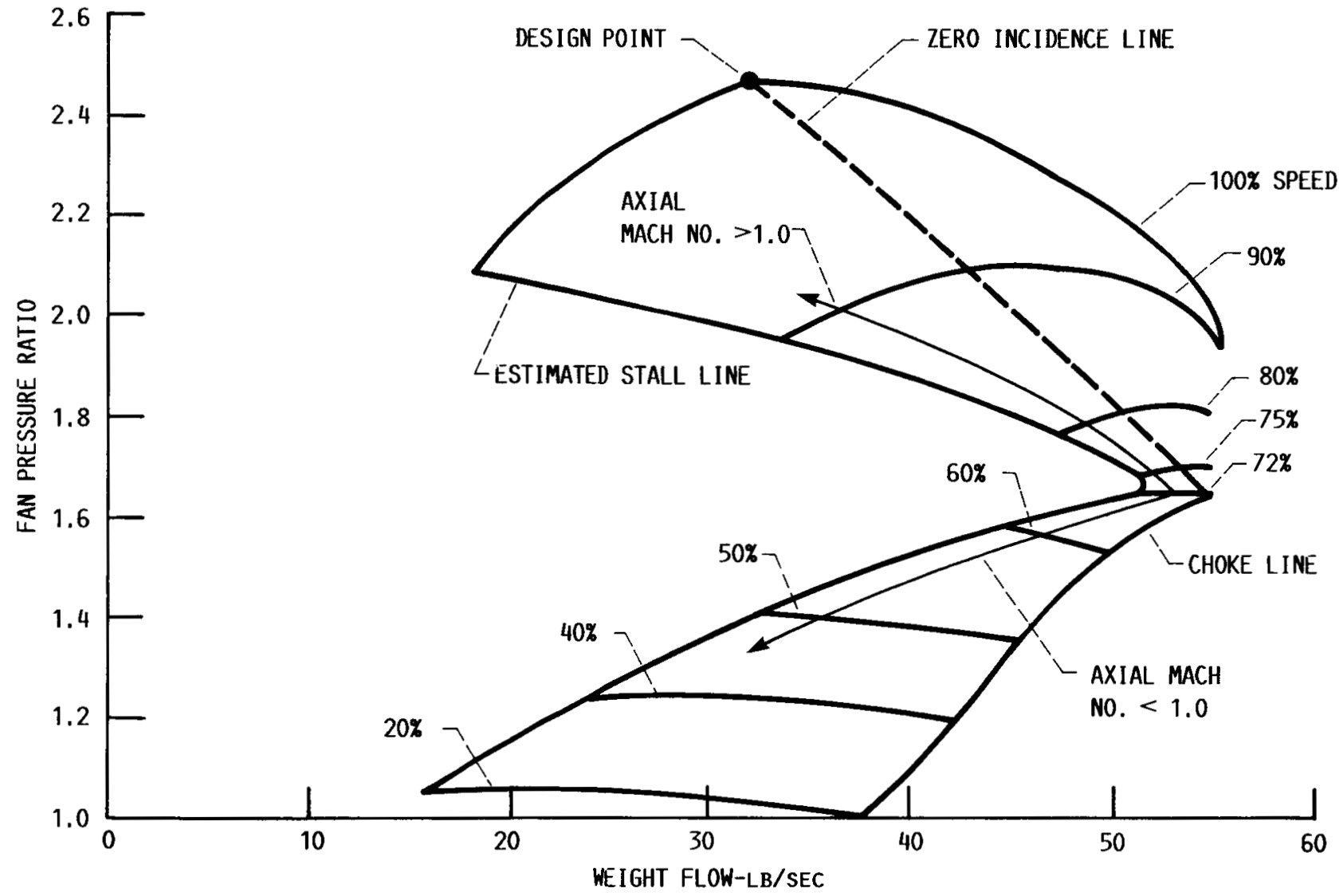

FIgURE 13. - PREDICTED STF FAN PERFORMANCE MAP. 


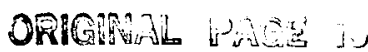

\section{OF POOR QUALTY}

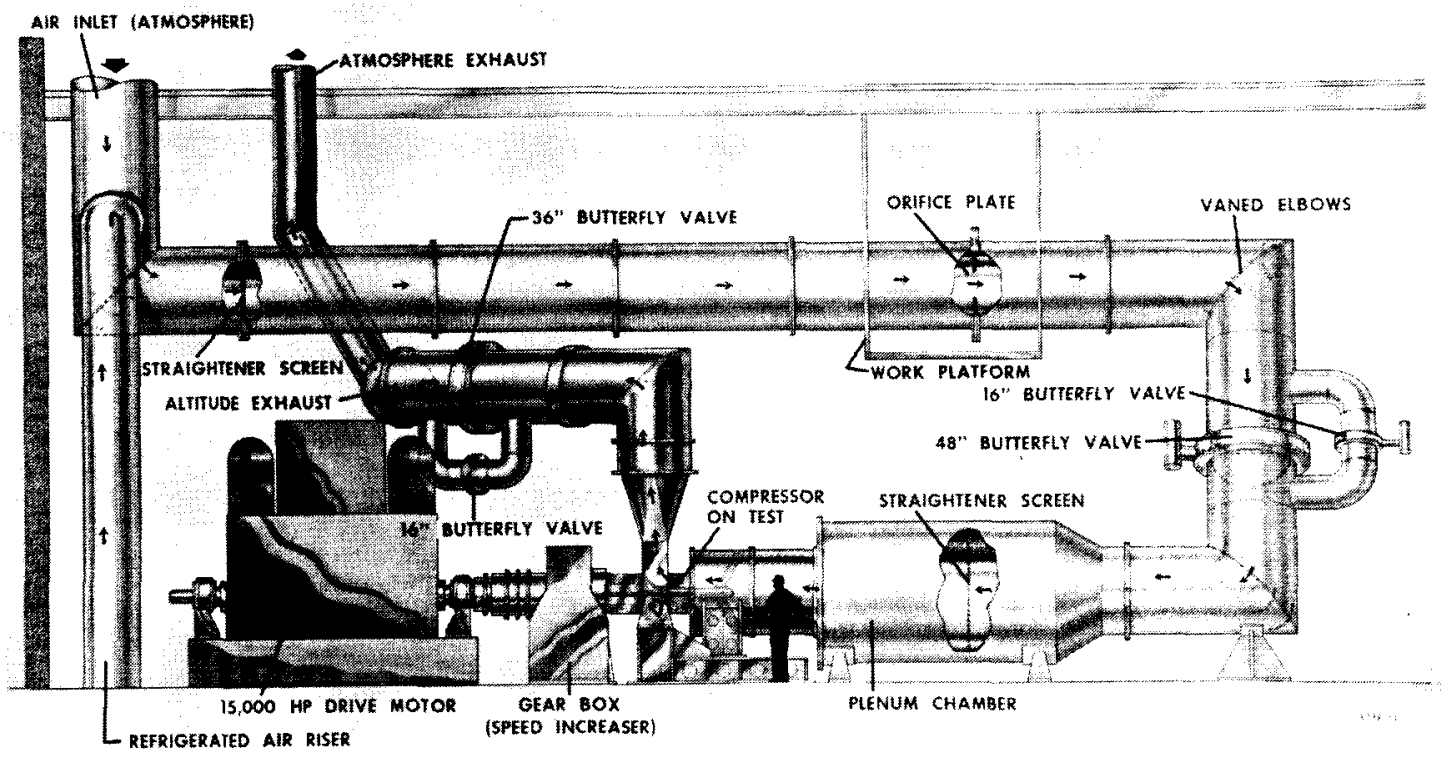

FIGURE 14. - MULTISTAGE COMPRESSOR FACILITY. 









*For sale by the National Technical Information Service, Springfield, Virginia 22161 